\title{
Intellectually Disabled Victims of Sexual Abuse in the Criminal Justice System
}

\author{
Susanna Niehaus, Paula Krüger, Seraina Caviezel Schmitz \\ Department of Social Work, Lucerne University of Applied Sciences and Arts, Lucerne, Switzerland \\ Email: susanna.niehaus@hslu.ch
}

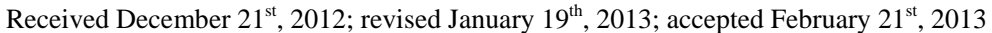

\begin{abstract}
People with intellectual disabilities face an exceptionally high risk of being victims of sexual abuse and thereby becoming involved in the criminal justice system. Coping effectively with this system is enough of a challenge for those without disability, but it is far more difficult for the intellectually disabled. As a result, greater attention needs to be paid to their needs. From the opposite perspective, dealing with people with intellectual disabilities is a challenge for experts in forensic and criminal law practice. This short report presents the background, design, and preliminary findings of a study examining how far the police, judges, prosecutors, forensic-psychiatric experts, forensic-psychological experts, and social workers are able to ensure that victims with intellectual disabilities experience procedural fairness by taking their particular needs into account in everyday criminal proceedings.
\end{abstract}

Keywords: Intellectual Disability; Sexual Abuse; Attitudes; Rape Myths; Criminal Justice System

\section{Introduction}

People with intellectual disabilities suffer from a disproportionately high exposure to sexual abuse (Bureau of Justice Statistics, 2012; Schröttle, Hornberg, Glammeier, Sellach, Kavemann, Puhe, \& Zinsmeister, 2012). Although they naturally do not form a homogeneous group of persons who are all equally at risk, there is no longer any doubt within the scientific community that individuals with intellectual disabilities are more vulnerable due to an accumulation of personal and social risk factors. That is, their specific socialization conditions and needs lead in various ways to an imbalance of power between them and their environment that greatly increases their probability of becoming victims of sexual abuse (Peckham, 2007; Rand, 2002; Schröttle et al., 2012; Senn, 1988; Sobsey, 1994; Trost, 2010; Walter, 2002). This power gap between offender and victim or the limited possibility of successfully fending off violence is considered to be a key mechanism for explaining sexual abuse (Cossins, 2000; Koss et al., 1994). For people with intellectual disabilities, the possibility of successfully fending off violence is limited in many ways. For example, even today, they have often not received an adequate sexual education and have had little opportunity to gather sexual experiences (Allington, 1992; Trost, 2010). As a result, they lack both the ability to differentiate and the language not only to communicate what they want and do not want but also to report potential abuse (Walter, 2005). A further aspect is that a limited cognitive capacity reduces the ability to perceive and appropriately interpret danger signals (Tyler, Hoyt, \& Withbeck, 1998). Because of their restricted ability to grasp situations, they may, for example, not comprehend the intentions of a potential offender until it is too late (Senn, 1988). Moreover, negative feedback from their social environment contributes to low self-esteem, and low selfesteem makes it harder to set limits (Becker, 1995). In addition, people with intellectual disabilities generally have less effective social networks and are highly dependent both economically and personally on a range of individuals. Finally, through their more strongly structured daily routines, they are more used to adapting themselves to externally imposed directives. Such reduced self-determination also imposes major constraints on the possibilities of putting up resistance when, in line with learning theory, they may anticipate that this will lead to negative reactions from important reference persons (Peckham, 2007; Senn, 1988; Zemp, 2002). In turn, the greater the ease in overcoming their resistance and their protective mechanisms, the more attractive they might be from the perspective of offenders. Surveys of offenders have revealed that they select victims according to their perceived vulnerability (e.g., their lack of confidence; see Conte, Wolf, \& Smith, 1989; Elliott, Browne, \& Kilcoyne, 1995; Shuker, 1980, cited in Longo \& Gnochenour, 1981). Hence, from the perspective of potential offenders, people with intellectual disabilities might well seem to be ideal victims - the greater their limitations, the lower the risk of being reported, charged, and prosecuted for an offence.

If persons with intellectual disabilities have become victims of sexual abuse, reporting the crime confronts them with a criminal justice system whose complexity makes exceptionally high demands on their ability to communicate (Milne \& Bull, 1999). Even individuals with no disability are scarcely familiar with the rules and procedures of the legal system and are often particularly unable to handle the complexity and otherness of legal language. And persons only need to have reading difficulties to have less chance of asserting their rights (Inclusion Europe, 2003). Exclusion becomes even more probable with increasing disability and a decreasing willingness of the system to adjust to an otherness in order to compensate the disadvantages that this otherness may entail (Wansing, 2007). This willingness will probably be even lower the more negative the attitudes toward people with intellectual disabilities.

However, for many years, the sexual abuse of intellectually disabled men and women was simply taken to be inconceivable; 
and it was correspondingly a long time before research in the German-speaking countries (compared to, e.g., Australia, Great Britain, and North America) started to address this field. This failure to recognize the problem for such a long time probably relates strongly to social perception processes (Oosterhoorn \& Kendrick, 2001). Numerous studies have shown that attitudes toward people with intellectual disabilities are mostly negative; and a vague, deficit-oriented picture of intellectual disability dominates broad areas of society (e.g., Antonak \& Livneh, 1991). Even today, despite fundamental changes for the better, it is still possible to confirm negative attitudes toward people with intellectual disabilities (see, for a review, Scior, 2011).

There also seem to be false assumptions about intellectual disability. In line with Senn (1988), these can be called myths of intellectual disability. They include, for example, the myth that intellectually disabled persons are not aware of what is going on around them or the myth that their supposed unattractiveness protects them from sexual abuse. Most myths are based on an infantilization, that is, on the idea that intellectual disability rules out being adult (Robey, Beckley, \& Kirschner, 2006; Walter, 2002). The general rape myths are that sexual assaults are less an abuse of power than the exercise of an aggressive form of normal sexuality triggered by the attractiveness of the victim (Burt, 1980; Burt \& Albin, 1981; Gerger, Kley, Bohner, \& Siebler, 2007). These combined with the purported protecttion of individuals with intellectual disabilities through their supposed lack of attractiveness result in different myths generating a way of thinking that makes the sexual abuse of the intellectually disabled seem unlikely. It is conceivable that the professions involved in criminal proceedings are also not immune to such social perception processes (e.g., Krahé, 2012), particularly when their members know little about intellectual disability. In that case, there is also a risk that such myths may impact on case processing. Evaluating statements and appraiseing persons both play a central role in any criminal investigations and proceedings, and when it comes to the victim, there is a particularly strong focus on the competence to stand trial and to testify along with the credibility of that testimony. In this context, both a deficit-oriented outlook and the acceptance of widespread myths could have a negative effect for participants with intellectual disability. Particularly when those involved in proceedings have little knowledge about intellectual disability, disability-specific stereotypes may dominate their perceptions and conclusions.

Although there are legal norms that explicitly take account of people with intellectual disabilities in criminal proceedings, the norm of equality before the law depends essentially on it being implemented by the representatives of the forensic and criminal law professions (Tag, Schmidt, \& Wiesner, 2006). To ensure that the aforementioned power imbalance, which has already contributed toward their becoming a victim, does not persist here as a lack of power to lodge one's grievance before the criminal justice system, victims depend on the representatives of the professional groups involved complying with these norms and taking their particular concerns and needs into account. Nonetheless, there is a persistently all-encompassing deficit orientation and unwillingness on the part of representatives of the legal system to consider the needs of people with intellectual disabilities and adapt to these needs. This has been criticized far more strongly in Great Britain, Australia, and Canada (e.g., Brennan \& Brennan, 1994) than in Austria, Germany, and Switzerland. Referring to the Canadian criminal justice system, for example, Endicott (1992: p. 5) gets to the heart of the problem of the lack of participation of the intellectually disabled: “All too often a person's perceived inability to do some things is translated by legal processes into a finding of inability to do anything. The law has not demonstrated much capacity to find ways in which the person's special needs can be accommodated so that he or she can participate in ordinary human activities, including the activity of doing justice in society.” Milne and Bull (1999) also criticize an all-encompassing deficit orientation in Great Britain's criminal justice system and point to a failure to take the special needs of people with intellectual disabilities into account-a failure that expresses itself in, for example, sweeping assumptions about the inability to testify or also in a well-meant but nonprofessional prompting of the contents of testimony through leading questions.

Any serious effort toward integration cannot be achieved through an all-encompassing deficit orientation or through an indifference that tries to ignore individual characteristics. Instead, it is necessary to accept the existing distance from the norm as a fact. Primarily, this requires professionals to think about how they handle people with intellectual disabilities when they have to deal with them in their work. An adequate consideration of special needs requires, in turn, knowledge about intellectual disability and the associated special difficulties (e.g., in communication) as well as competencies in implementing that knowledge. This additionally assumes a basic willingness to adjust to otherness. How far these preconditions can be taken as given in the relevant professional groups in German-speaking countries was the topic of a research project launched at the end of 2008 by the Lucerne University of Applied Sciences and Arts.

One can certainly ascertain an increase in scientific interest in intellectual disabilities, and there have been a few isolated studies on the more general problems that people with intellectual disabilities face when dealing with the police (e.g., Brennan \& Brennan, 1994), on assessing the credibility of children's testimonies as a function of the degree of disability (e.g., Peled, Iarocci, \& Connolly, 2004), and on the quality of the testimony of people with intellectual disabilities (e.g., Kebbell, Hatton, \& Johnson, 2004). However, to the best of the authors' knowledge, no study up to now has systematically investigated the relation between knowledge, attitudes, and the acceptance of myths, and examined how these impact on intellectually disabled victims of sexual abuse, while simultaneously taking into account the perspectives of all those involved in criminal proceedings. Therefore, the goal of the present project was to gain a first description of the situation of adult intellectually disabled victims of sexual abuse in the criminal justice system.

This article presents a short sketch of the research project that was based on the mixed-methods design (Mayring, Huber, Gürtler, \& Kiegelmann, 2007) illustrated in Figure 1.

\section{Research Questions and Key Hypotheses}

The research project focused on processes in the social perception of adult intellectually disabled victims of sexual abuse to be found among the professional groups involved in criminal justice proceedings in Austria (AT), Germany (DE), and German-speaking Switzerland $(\mathrm{CH})$ along with the knowledge these groups possess about intellectual disability (see Block I in Figure 1). In detail, the project was designed to deliver answers to the following questions: 


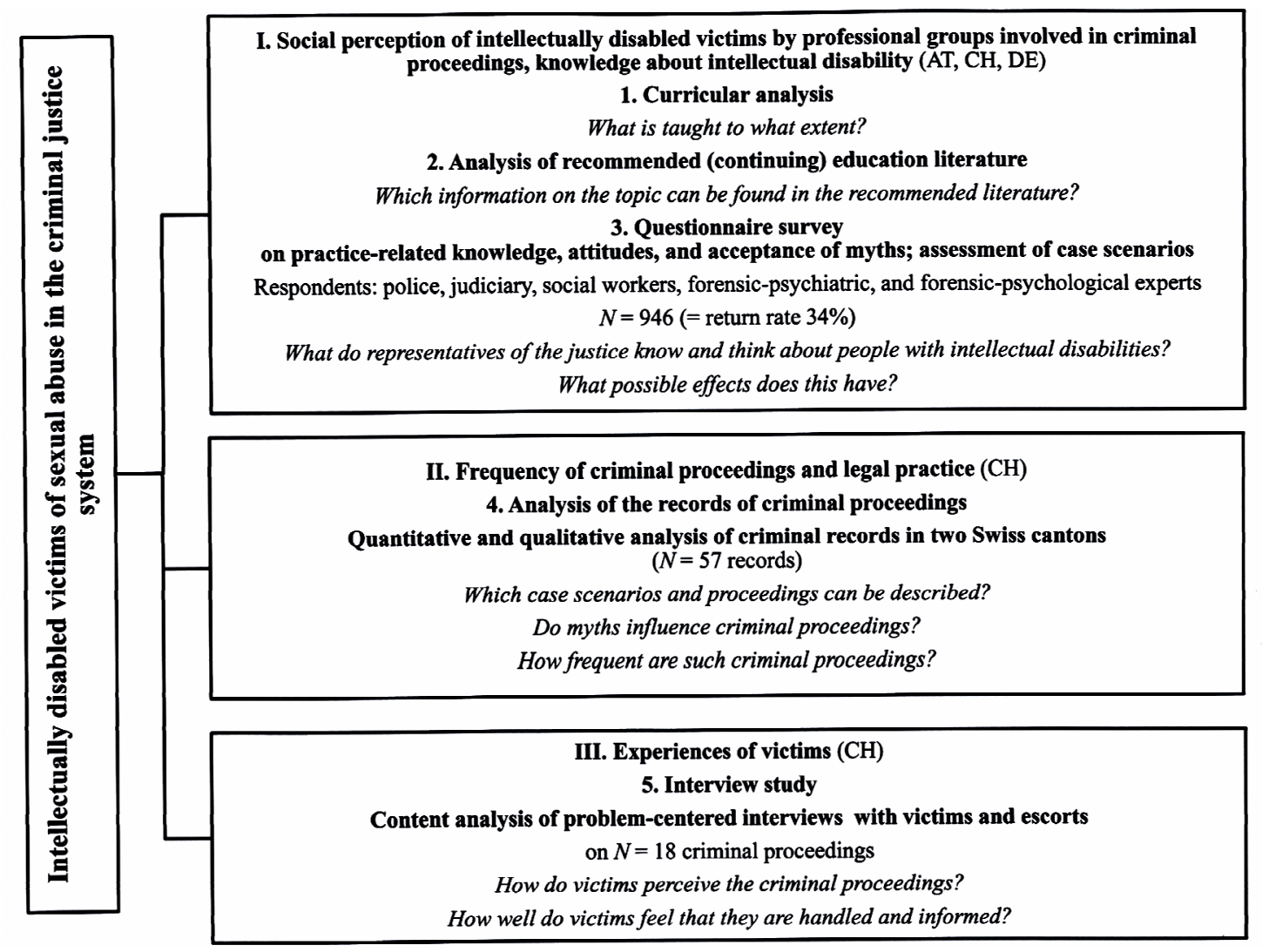

Figure 1.

Research design and questions.

1) To what extent are which professional groups involved in criminal proceedings taught what about intellectual disability during their (continuing) education?

2) Which information is to be found in the literature recommended to them by their lecturers?

3) What do representatives of the justice system (judiciary and public prosecutors), the police, psychological experts, psychiatric experts, and social workers know and think about people with intellectual disabilities, and how does this impact on their assessment of case scenarios?

4) How frequent are such criminal proceedings, what are the case scenarios, and how do proceedings unfold for sexual offences against intellectually disabled victims (the "white figure” of reported offences in criminal proceedings)? Do myths impact on real criminal proceedings?

5) How do the victims themselves perceive criminal proceedings? How do they think they are treated and informed?

The following relationships were hypothesized for the third research question: Little knowledge about intellectual disability would be accompanied by a more negative attitude toward the intellectually disabled, and this would contribute to the maintenance of disability-specific myths. The more negative the attitudes and the stronger the acceptance of myths, the lower, in turn, for example, the fundamental willingness to consider the testimony of an intellectually disabled victim as credible.

\section{Design of the Research Project}

Research question 1 was answered by analyzing the (con- tinuing) education curricula; Research question 2, by analyzing the literature recommended by lecturers. Both analyses served initially to determine which specialized knowledge was theoretically available to each professional group during (continuing) education.

Research question 3 was answered through a written survey of the relevant professions engaged in criminal proceedings. The major task here was to develop a quasiexperimental research design to assess the relation between the predictor variables attitude, knowledge, and acceptance of myths on the one side and measures for the intuitive assessment of case scenarios on the other. To assess the attitudes toward people with intellectual disability (Scale 1), Akrami, Ekehammar, Claesson, and Sonnander's (2006) classical and modern scales of attitudes toward people with intellectual disabilities were translated into German, the items were adapted to the German language, and additional items were included to assess, for example, the important domain of the sexuality of people with intellectual disabilities. Rape myths acceptance (Scale 2) was assessed with only slightly adjusted items from existing scales, namely, the Acceptance of Modern Myths about Sexual Aggression (AMMSA) Scale from Gerger et al. (2007) and the Rape Myths Acceptance (VMA) Scale from Bohner et al. (1998). The acceptance of disability-specific myths (Scale 3), such as the myth that supposed unattractiveness protects people with intellectual disabilities from sexual abuse, was assessed with a specially developed scale, and a test was also developed to assess knowledge on intellectual disability and sexual abuse (Scale 4). All assessment instruments were first evaluated in a comprehensive 
prestudy that gave separate pretests to different populations and then optimized them for the actual data collection with factor analyses and scale analyses. Dependent variables (e.g., the attribution of credibility) were assessed by asking participants to rate case scenarios in which the degree of disability of the victim of sexual abuse was varied as the independent variable (no, light, and moderate intellectual disability).

Participants were recruited through professional associations, Internet searches, and telephone searches. A total of 3185 questionnaires were sent out with stamped-addressed envelopes and 3059 persons were contacted. These were 516 forensic-psychiatric experts (complete population in AT, CH, DE), 652 forensic-psychological experts (complete population in AT, $\mathrm{CH}, \mathrm{DE}$ ), 430 police officers (judgment sample in $\mathrm{CH}$ ), 492 social workers in victim counseling centers and legal guardianship offices (Amtsvormundschaften) (judgment sample in $\mathrm{CH}$ ), and 969 judicial staff (approximately one-half public prosecutors [complete population in $\mathrm{CH}$ ] and one-half criminal law judges including lay judges [stratified random sample in $\mathrm{CH}$ ]). The return rate was approximately $34 \%$.

Research question 4 was addressed with a quantitative and qualitative analysis of the records of criminal proceedings for sex crime cases from the years 2000-2009 in two Germanspeaking Swiss cantons. This analysis was designed to gain information not only on the frequency of such criminal proceedings and the scenarios of these crimes but also on whether participants in the proceedings referred to myths when arguing cases of the sexual abuse of people with intellectual disabilities; that is, whether these myths were effective in proceedings (see Block II in Figure 1). Because the official registers did not specify whether a victim had an intellectual disability, it was necessary to use information in these registers to preselect cases in which to search directly for indications of intellectual disability. A matrix was developed to assess not only quantitative data on the victim, the accused, and proceedings but also quailtative data on the potential use of myths about sexual abuse and intellectual disability by professionals involved in the proceedings. The qualitative data were analyzed with Atlas.ti ${ }^{\odot}$ computer software and classified on the basis of Mayring's (2002) qualitative content analysis.

Although the study focused particularly on the social perception processes that reflect the external outlook on intellectual disability, the authors strived to take systematic account of the different perspectives; that is, to find out not only what the actors in the criminal justice system had to say but also the victims themselves (see Block III in Figure 1). Victims were accessed through professional groups whose work brings them into direct contact with victims of sexual abuse. Letters were written to all members of German-Swiss bar associations active in the assistance of victims as well as further nonmembers and staff at victim support centers. Victims' perceptions and appraisals of proceedings were assessed with semistructured problem-centered interviews focusing particularly on the framing conditions, on the inclusion of special rules to assist victims in criminal proceedings, on information given to the victim, and on measures to ensure understanding. The interview conditions were adapted to the individual needs of the respondents (duration, use of breaks, escort) based on a procedure reported by Milne and Bull (1999). The interviews were recorded, transcribed, and analyzed with the help of Atlas.ti ${ }^{\odot}$ computer software and classified on the basis of Mayring's (2002) qualitative content analysis.

\section{Preliminary Findings and Outlook}

The analyses of curricula and the literature recommended by lecturers already showed that disability-related topics are addressed, at best, in only a very rudimentary way in the (continuing) education of relevant professional groups. This already suggests that the project would find a lack of practice-related knowledge. In view of the low curricular coverage of the topic, it seems exceptionally questionable whether representatives of the judiciary and the police, in particular, are taught sufficient practical knowledge in their (continuing) education in Switzerland to enable them to address the special needs of people with intellectual disabilities. This makes it neither surprising nor reprehensible when proceedings reveal a degree of awkwardness in handling intellectually disabled victims. There is a clear need for improvements to (continuing) education. It will be necessary to analyze how much the representatives of different professional groups actually know just as carefully as the relations between knowledge, acceptance of myths, attitudes, and case evaluations.

Preliminary results on the analyses of case records revealed statements confirming the efficacy of both myths over intellecttual disability and general rape myths in criminal law practice. What makes this finding so revealing is that even when those involved in proceedings have recourse to certain myths, they do not necessarily express this in official documents because these are designed to be used legally. It was also notable in this context that it was not only persons who rarely had anything to do with people with intellectual disabilities who applied these myths but also representatives of medical and social professions who, to some extent, even worked with the victims.

Finally, the victims themselves also experience the consequences of being faced with a lack of specialized knowledge and the acceptance of myths. Preliminary analyses of the interviews with victims already indicated that the representatives of the investigating authorities do not seem to adapt their procedures sufficiently to the needs of people with intellectual disabilities. These particularly criticized the lack of information about the proceedings given to them as victims, the excessive length of proceedings, as well as the way they were treated as victims-particularly the lack of and incorrect knowledge about intellectual disability and failure to take account of their needs during hearings.

Sexual abuse proceedings are always stressful for any victim. However, when the victim is intellectually disabled, further special aspects emerge (e.g., they are more easily irritated, have difficulties in recalling from memory) that can make the situation even more difficult. These special aspects need to be integrated into the design of criminal proceedings in order to enable people with intellectual disabilities to also experience procedural fairness. Criticism of the length of proceedings and a lack of sufficient information on the state and the outcome of proceedings are already a general finding from international surveys of victims without learning difficulties (Frazier \& Haney, 1996). However, such framing conditions have further conesquences when the victim is intellectually disabled. If, for example, an intellectually disabled person has to give testimony several months or even one year after the offence is reported, this greatly reduces the quality of recall-an easily avoided procedural error that may, nonetheless, have a decisive impact on the outcome of criminal proceedings. Knowledge gaps and misconceptions could also offer an explanation for the observation 
that those involved in proceedings do not adjust these sufficiently to the needs of individuals with intellectual disabilities. Whereas some of the aspects respondents complain about are unavoidable in a due process of law (e.g., a thorough and critical examination of whether an accusation can be proved), there can be no question that every unnecessary stress, triggered, for example, by the inappropriate behavior of those involved in proceedings needs to be avoided (Volbert, 2012). Such unnecessary stress should be ruled out in principle-not just for victims with intellectual disability, but particularly for such victims.

Naturally, the present study has several limitations. When working with data on the number of cases in the "white figure" of criminal proceedings, it is always necessary to assume a major "dark figure” in this area of offending (Fitzgerald, 2006; Temkin \& Krahé, 2008) and particularly in this target group, because studies consistently suggest that, although the sexual abuse of people with disabilities is common, the proportion of cases resulting in prosecution is very low (Green, 2001). However, even when working with the white figure of criminal proceeding studied here, the way in which cases had to be acquired and the probability that those involved in proceedings were not always aware of the victim's intellectual disability will have resulted in a marked underestimation of the number of court cases involving sexual offences against persons with intellectual disabilities. When analyzing the records of criminal proceedings, it should also be taken into account that these are not always complete and their documentation inevitably involves selection processes and distortions. Therefore, when interpreting the results, one should bear in mind that this is, in principle, an analysis of "reality according to the records." In this light, it is even more remarkable that the case records analyzed here reveal statements confirming the impact of myths. Turning to the findings obtained from interviews, it should be noted that such an explorative study cannot claim to be representative. In addition, retrospectively evaluating experiences in criminal proceedings may well be hampered not only by motivational problems in recruiting respondents but also and in particular by cognitive problems in surveying this target group. Future studies should try to avoid these problems by, for example, surveying respondents immediately after an offence is reported to the police and then following them up using a longitudinal design. Nonetheless, the main findings from the interviews are clearly supported by those from the questionnaire survey and the analysis of case records.

\section{Conclusion}

For a long time, sexual abuse of men and women with intellectual disabilities was taken to be inconceivable (Fegert, Jeschke, Thomas, \& Lehmkuhl, 2006). Social perception processes probably contributed to the failure to recognize this problem. The present research project examined the significance of both such processes and knowledge deficits within the framework of criminal proceedings for sexual offences. When setting up the project, the managers of two renowned organizations campaigning for the rights of people with intellectual disability located both in Switzerland and abroad seriously doubted any large-scale sexual abuse of people with intellectual disability. Although the public outcry in February 2011 when a social worker confessed to sexually abusing 114 mostly physically and intellectually disabled persons while working in Switzer- land and Germany may have made the general public more aware that this may be a misperception, it has not solved the underlying problem. The managers' doubts cited here illustrate what the preliminary findings of the present study already suggest: There are numerous misconceptions about this topic, and in no way just among representatives of the police and judiciary, but also among persons who should actually know more about it through their training and their work. This initial situation already leads us to the following conclusion: If the current discussion on the inclusion of people with intellectual disability is to be taken seriously, there is still a great deal to do.

\section{Acknowledgements}

We thank R. Berli, S. Flindt, K. Trost, and M. Zöhner for their support during various phases of the project. This study has been funded by the Swiss National Science Foundation.

\section{REFERENCES}

Akrami, N., Ekehammar, B., Claesson, M., \& Sonnander, K. (2006). Classical and modern prejudice: Attitudes toward people with intellectual disabilities. Research in Developmental Disabilities, 27, 605617. doi:10.1016/j.ridd.2005.07.003

Allington, C. L. J. (1992). Sexual abuse within services for people with learning disabilities: Staffs' perceptions, understandings of and contact with the problems of sexual abuse. Mental Handicap, 20, 59-63. doi:10.1111/j.1468-3156.1992.tb00660.x

Antonak, R. F., \& Livneh, H. (1991). Survey research on attitudes. In J. L. Matson, \& J. A. Mulick (Eds.), Handbook of mental retardation (pp. 552-568). New York: Pergamon Press.

Becker, M. (1995). Sexual abuse of girls with intellectual disability: Data and background. Heidelberg: Edition Schindele.

Bohner, G., Reinhard, M.-A., Rutz, S., Sturm, S., Kerschbaum, B., \& Effler, D. (1998). Rape myths as neutralizing cognitions: Evidence for a causal impact of anti-victim attitudes on men's self-reported likelihood of raping. European Journal of Social Psychology, 28, 257-268.

doi:10.1002/(SICI)1099-0992(199803/04)28:2<257::AID-EJSP871> 3.0.CO;2-1

Brennan, M., \& Brennan, R. (1994). Cleartalk: Police responding to intellectual disability. Warra: Charles Sturt University.

Bureau of Justice Statistics (2012). National Crime Victimization Survey 2008-2011. http://bjs.ojp.usdoj.gov/index.cfm?ty=pbdetail\&iid =4574

Burt, M. R. (1980). Cultural myths and support for rape. Journal of Personality and Social Psychology, 38, 217-230. doi:10.1037/0022-3514.38.2.217

Burt, M. R., \& Albin, R. S. (1981). Rape myths, rape definitions, and probability of conviction. Journal of Applied Social Psychology, 11, 212-230. doi:10.1111/j.1559-1816.1981.tb00739.x

Conte, J. R., Wolf, S., \& Smith, T. (1989). What sexual offenders tell us about prevention strategies. Child Abuse and Neglect, 13, 293-301. doi:10.1016/0145-2134(89)90016-1

Cossins, A. (2000). Masculinities, sexualities and child sexual abuse. The Hague: Kluwer Law International.

Elliott, M., Browne, K., \& Kilcoyne, J. (1995). Child sexual abuse prevention: What offenders tell us. Child Abuse and Neglect, 19, 579594. doi:10.1016/0145-2134(95)00017-3

Endicott, E. (1992). Technical report: The impact of Bill c-15 on persons with communication disabilities. Ottawa: Research and Development Directorate, Department of Justice.

Fegert, J. M., Jeschke, K., Thomas, H., \& Lehmkuhl, U. (2006). Sexual self-determination and sexual abuse. Weinheim: Juventa.

Fitzgerald, J. (2006). The attrition of sexual assault offences from the New South Wales Criminal Justice System. Contemporary Issues in Crime and Justice, No. 92. Sydney: NSW Bureau of Crime Statistics and Research. 
Frazier, P. A., \& Haney, B. (1996). Sexual assault cases in the legal system: Police, prosecutor, and victim perspectives. Law and Human Behavior, 20, 607-628. doi:10.1007/BF01499234

Gerger, H., Kley, H., Bohner, G., \& Siebler, F. (2007). The Acceptance of Modern Myths About Sexual Aggression (AMMSA) scale: Development and validation in German and English. Aggressive Behavior, 33, 420-440. doi:10.1002/ab.20195

Green, G. (2001). Vulnerability of witnesses with learning disabilities: Preparing to give evidence against a perpetrator of sexual abuse. British Journal of Learning Disabilities, 29, 103-109. doi:10.1046/j.1468-3156.2001.00136.x

Inclusion Europe (2003). Justice, rights and inclusion for people with intellectual disabilities. Brussels: Inclusion Europe.

Kebbell, M. R., Hatton, C. \& Johnson, S. D. (2004). Witnesses with intellectual disabilities in court: What questions are asked and what influence do they have? Legal and Criminological Psychology, 9, 23-35. doi:10.1348/135532504322776834

Koss, M. P., Goodman, L. A., Browne, A., Fitzgerald, L. F., Keita, G. P., \& Russo, N. F. (1994). No safe haven: Male violence against women at home, at work, and in the community. Washington DC: American Psychological Association. doi:10.1037/10156-000

Krahé, B. (2012). Social reactions to primary victimization: Influence of stereotyped judgment patterns. In S. Barton, \& R. Kölbel (Eds.), Ambivalenzen der Opferzuwendung des Strafrechts (pp. 159-175). Baden: Nomos.

Mayring, P. (2002). Qualitative content analysis: Research instrument or mode of interpretation? In M. Kiegelmann (Ed.), The role of the researcher in qualitative psychology (pp. 139-148). Tübingen: Ingeborg Huber.

Mayring, P., Huber, G. L., Gürtler, L., \& Kiegelmann, M. (2007). Mixed methodology in psychological research. Rotterdam: Sense Publishers.

Milne, R., \& Bull, R. (1999). Investigative interviewing: Psychology and practice. Chichester: Wiley.

Longo, R. E., \& Gnochenour, C. (1981). Sexual assault of handicapped individuals. Journal of Rehabilitation, 47, 24-27.

Oosterhoorn, R., \& Kendrick, A. (2001). No sign of harm: Issues for disabled children communicating about abuse. Child Abuse Review, 10, 243-253. doi:10.1002/car.697

Peckham, N. G. (2007). The vulnerability and sexual abuse of people with learning disabilities. British Journal of Learning Disabilities, 35, 131-137. doi:10.1111/j.1468-3156.2006.00428.x

Peled, M., Iarocci, G., \& Connolly, D. (2004). Eyewitness testimony and perceived credibility of youth with mild intellectual disability. Journal of Intellectual Disability Research, 48, 699-703. doi:10.1111/j.1365-2788.2003.00559.x

Rand, M. R. (2002). Crimes against persons with disabilities. In D. Levinson (Ed.), Encyclopedia of crime and punishment (Vol. 1, pp. 394-397). Thousand Oaks, CA: Sage. doi:10.4135/9781412950664.n102

Robey, K. L., Beckley, L., \& Kirschner, M. (2006). Implicit infantilizing attitudes about disability. Journal of Developmental and Physical Disabilities, 18, 441-453. doi:10.1007/s10882-006-9027-3

Schröttle, M., Hornberg, C., Glammeier, S., Sellach, B., Kavemann, B., Puhe, H., \& Zinsmeister, J. (2012). Living conditions and stress of women with impairments and disabilities in Germany. Journal Netzwerk Frauen- und Geschlechterforschung NRW, 30, 60-64.

Scior, K. (2011). Public awareness, attitudes and beliefs regarding intellectual disability: A systematic review. Research in Developmental Disabilities, 32, 2164-2182. doi:10.1016/j.ridd.2011.07.005

Senn, C. Y. (1988). Vulnerable: Sexual abuse and people with an intellectual handicap. Toronto: The G. Allan Roeher Institute.

Sobsey, D. (1994). Violence and abuse in the lives of people with disabilities: The end of silent acceptance. Baltimore, MD: Paul H. Brookes.

Tag, B., Schmidt, J., \& Wiesner, S. (2006). The disabled child in criminal law: As victim and offender. In F. Sprecher, \& P. Sutter (Eds.), Das behinderte kind im schweizerischen recht (pp. 115-142). Zürich: Schulthess.

Temkin, J., \& Krahé, B. (2008). Sexual assault and the justice gap: A question of attitude. Portland, OR: Hart Publishing.

Trost, R. (2010). Sexuality and sexual abuse in people with intellectual disability. In M. Clauß, M. Karle, M. Günter, \& G. Barth (Eds.), Sexuelle Entwicklung-sexuelle Gewalt (2nd ed., pp. 22-40). Lengerich: Pabst Science Publishers.

Tyler, K. A., Hoyt, D. R., \& Withbeck, C. B. (1998). Coercial sexual strategies. Violence and Victims, 13, 47-61.

Volbert, R. (2012). Injured parties in criminal proceedings: Positive effects or secondary victimization? In S. Barton, \& R. Kölbel (Eds.), Ambivalenzen der opferzuwendung des strafrechts (pp. 197-212). Baden: Nomos.

Walter, J. (2002). Assaults on the sexual self-determination of people with intellectual disability. In J. Walter (Ed.), Sexualität und geistige behinderung (5th ed., pp. 414-420). Heidelberg: Universitätsverlag Winter, Edition S.

Walter, J. (2005). Self-determined sexuality as a human right: Standards for dealing with the sexuality of disabled people. In J. Jerg, J. Armbruster, \& A. Walter (Eds.), Selbstbestimmung, assistenz und teilhabe (pp. 105-122). Stuttgart: VEG.

Wansing, G. (2007). Disability: Leading to inclusion or exclusion? On the construction of paradoxical life courses in the modern society. In A. Waldschmidt, \& W. Schneider (Eds.), Disability studies, kultursoziologie und soziologie der behinderung (pp. 275-297). Bielefeld: transcript Verlag.

Zemp, A. (2002). Sexualized violence against people with disabilities in institutions. Praxis der Kinderpsychologie und Kinderpsychiatrie, 51, 610-625. 